\title{
PELATIHAN OLIMPIADE MATEMATIKA TINGKAT SMP/MTS DI MTS DARUL HIKMAH NGOMPAK NGRAMBE NGAWI TAHUN PELAJARAN 2019/2020
}

\author{
Heri Cahyono \\ STKIP Modern Ngawi \\ (hericahyono@live.com, 081231248214)
}

\begin{abstract}
ABSTRAK
Pelajaran matematika adalah bagian utama dari masyarakat ilmiah yang mampu bergerak dinamis seiring perkembangan zaman. Beragam aktivitas telah dilakukan oleh para pelajar dalam mengukuhkan perannya sebagai komponen pembangunan. Aksi-aksi produktif, inovatif, dan kreatif yang diwujudkan oleh pelajar tidak pernah meninggalkan nuansa ilmiah yang menjadi ciri khasnya. Olimpiade Matematika adalah salah satu bentuk kompetisi untuk meningkatkan kualitas sumber daya manusia. Diharapkan dengan adanya kegiatan olimpiade matematika dapat merangsang munculnya idealisme baru dalam dunia matematika.

Pengabdian kepada masyarakat ini berupa pelatihan kepada siswa dan siswi MTs Darul Hikmah Ngompak, kecamatan Ngrambe, kabupaten Ngawi, Jawa Timur. Metode yang digunakan adalah dengan melakukan pembimbingan langsung dengan beberapa metode, diantaranya metode ceramah, tanya jawab, simulasi, dan evaluasi.

Kesimpulan dari pengabdian ini adalah dengan melakukan pembimbingan lebih intensif pada siswa/siswi MTs Darul Hikmah Ngompak pada materi olimpiade matemika, maka kemampuan dan pemahaman siswa/siswi dalam pengerjaan olimpiade akan semakin baik.
\end{abstract}

Kata kunci : Olimpiade, Matematika, Pembelajaran siswa

\section{ABSTRACT}

Mathematics lessons are a major part of the scientific community that is able to move dynamically with the times. Various activities have been carried out by students in strengthening their role as a component of development. Productive, innovative, and creative actions that are realized by students never leave the scientific nuances that characterize them. Mathematics Olympiad is a form of competition to improve the quality of human resources. It is hoped that the mathematics olympiad activity can stimulate the emergence of new ideals in the world of mathematics.

This community service is in the form of training for students at MTs Darul Hikmah Ngompak, Ngrambe sub-district, Ngawi district, East Java. The method used is direct guidance with several methods, including lecture methods, question and answer, simulation, and evaluation.

The conclusion of this service is that by providing more intensive guidance to students of MTs Darul Hikmah Ngompak on the mathematics olympiad material, the students' abilities and understanding in the Olympiad work will be better.

Keywords : Olympics, Mathematics, Student learning 


\section{Pelatihan Olimpiade Matematika Tingkat SMP/MTs Di MTs Darul Hikmah Ngompak Ngrambe Ngawi Tahun Pelajaran 2019/2020}

\section{PENDAHULUAN}

Olimpiade Matematika adalah salah satu bentuk kompetisi untuk meningkatkan kualitas sumber daya manusia. Diharapkan dengan adanya kegiatan olimpiade matematika dapat merangsang munculnya idealisme baru dalam dunia matematika. Berawal dari pandangan umum bahwa di era globalisasi saat ini kualitas sumber daya manusia harus ditingkatkan, sehingga dirumuskan bahwa hal mendasar yang patut dikembangkan adalah kreativitas dan intelektual manusia. Hal ini tidak terlepas dari bagaimana cara kita menjawab tantangan pembangunan nasional, terutama di bidang ilmu pengetahuan dan teknologi. Pelajaran adalah bagian utama dari masyarakat ilmiah yang mampu bergerak dinamis seiring perkembangan zaman. Beragam aktivitas telah dilakukan oleh para pelajar dalam mengukuhkan perannya sebagai komponen pembangunan. Aksi-aksi produktif, inovatif, dan kreatif yang diwujudkan oleh pelajar tidak pernah meninggalkan nuansa ilmiah yang menjadi ciri khasnya (Sudjana, 2009). Pada ajang kompetisi sain madrasah atau KSM (olimpiade yang diadakan Kementrian Agama) siswa/siswi dituntut untuk memiliki intelektual dan kreativitas yang tinggi, seleksi pada olimpiade yang ketat di tingkat Kabupaten, Provinsi, dan Nasional mengharuskan setiap sekolah yang mengikuti olimpiade melakukan bimbingan secara khusus kepada siswa/siswinya.

\section{BAHAN DAN METODE}

Pengabdian kepada masyarakat ini berupa pelatihan kepada siswa dan siswi MTs Darul Hikmah Ngompak, kecamatan Ngrambe, kabupaten Ngawi, Jawa Timur. Metode yang digunakan adalah dengan melakukan pembimbingan langsung dengan beberapa metode, diantaranya metode ceramah, tanya jawab, simulasi, dan evaluasi.

\section{HASIL}

Pada saat pelaksanaan pembimbingan siswa/siswi kebanyakan belum mampu mengerjakan soal-soal olimpiade dalam pembahasan bilangan, geometri, dan aljabar. Pada saat diberikan simulasi pengerjaan soal olimpiade, rata-rata siswa sudah mampu memahami materi bilangan, geometri, dan aljabar. Metode simulasi ini sangat penting diberikan kepada para peserta pelatihan untuk memberikan kesempatan mengaplikasikan materi yang sudah diberikan. Siswa langsung mengerjakan soal-soal yang ada di modul dan dapat langsung bertanya jika ada kesulitan atau masalah.

Saat Simulasi, siswa sudah terbiasa mengerjakan soal-soal dari modul pembelajaran, sehingga pada sesi evaluasi siswa sudah semakin lancar dalam pengerjaan soal-soal olimpiade. 


\section{Heri Cahyono}

\section{PEMBAHASAN}

Kegiatan ini untuk meningkatkan pemahaman dan keterampilan siswa/siswi MTs Darul Hikmah Ngompak Kecamatan Ngrambe dalam memahami konsep serta mengerjakan soal-soal olimpiade matematika, sehingga siswa/siswi MTs Darul Hikmah Ngompak dapat bersain dalam ajang olimpiade yang diselenggarakan oleh Kementrian Agama (KSM).

Menurut data yang ada sebagian besar siswa/siswi yang mengikuti olimpide masih belum menguasi materi-materi yang digunakan dalam olimpiade, diantaranya bilangan, geometri, dan aljabar sehingga digunakan beberapa metode untuk membantu masalah tersebut (Kuswidi, 2019). 1) Metode Ceramah; metode ceramah dipilih untuk memberikan penjelasan tentang konsep suatu materi serta cara pemecahan dari suatu materi (Sanjaya, 2006). Metode ini bertujuan untuk meningkatkan motivasi belajar siswa dan memberikan kesempatan kepada siswa untuk melatih kemampuan dalam komunikasi. 2) Metode Tanya Jawab; metode tanya jawab adalah metode mengajar yang memungkinkan terjadinya komunikasi langsung yang bersifat two ways traffic sebab pada saat yang sama terjadi dialog antara pemberi materi dengan siswa. Metode tanya jawab ini bertujuan untuk mengetahui sampai sejauh mana materi yang telah dikuasai oleh siswa, serta untuk merangsang siswa untuk lebih berpikir dan mengaitkan materi dan memberi kesempatan pada siswa untuk mengajukan masalah yang belum dipahami. 3) Metode Simulasi; metode simulasi ini sangat penting diberikan kepada para peserta pelatihan untuk memberikan kesempatan mengaplikasikan materi yang sudah diberikan. Siswa langsung mengerjakan soal-soal yang ada di modul dan dapat langsung bertanya jika ada kesulitan atau masalah. 4) Metode Evaluasi; keberhasilan kegiatan pengabdian masyarakat ini akan dievaluasi dengan mengamati dan memeriksa kebenaran jawaban atas pertanyaan-pertanyaan yang diberikan kepada siswa.

Kegiatan pengabdian diawali dengan penyampaian dasar-dasar materi yang dipelajari dalam menghadapi olimpiade di tingkat SMP/MTs. Setelah itu secara bertahap disampaikan dan dibahas serta memberikan contoh-contoh soal olimpide SMP/MTs baik tingkat lokal, regional, maupun nasional.

\section{KESIMPULAN DAN SARAN}

Kesimpulan dari pengabdian ini adalah dengan melakukan pembimbingan lebih intensif pada siswa/siswi MTs Darul Hikmah Ngompak pada materi olimpiade matemika, maka kemampuan dan pemahaman siswa/siswi dalam pengerjaan olimpiade akan semakin baik.

Saran bagi MTs Darul Hikmah Ngompak adalah lebih rutin dalam melakukan bimbingan intensif kepada siswa/siswi di kelas olimpiade dengan tujuan 


\section{Pelatihan Olimpiade Matematika Tingkat SMP/MTs Di MTs Darul Hikmah \\ Ngompak Ngrambe Ngawi Tahun Pelajaran 2019/2020}

agar siswa lebih matang dalam menghadapi soal-soal olimpiade.

\section{UCAPAN TERIMA KASIH}

Ucapan terimakasih disampaikan kepada LPPM STKIP Modern Ngawi, Kepala Madrasah MTs Darul Hikmah Ngompak Ngrambe, Wakil Kepala Kurikulum MTs Darul Hikmah Ngompak, Siswa/siswi MTs Darul Hikmah Ngompak Ngrambe, dan pihak-pihak lain yang telah membantu dalam pelaksanaan pengabdian ini.

\section{DAFTAR PUSTAKA}

Sanjaya, Wina. 2006. Strategi Pembelajaran. Jakarta: Kencana Prenada Media Group.

Sudjana. 2009. Penelitian Proses Motivasi Belajar Mengajar. Bandung: PT Remaja Rosdakarya.

Kuswidi, Iwan. 2019. Master Juara Olimpiade Sains Nasional Osn Matematika Smp-Mts \& Kunci Jawaban Pembahasan Soal. Media Karya.

\section{LAMPIRAN}

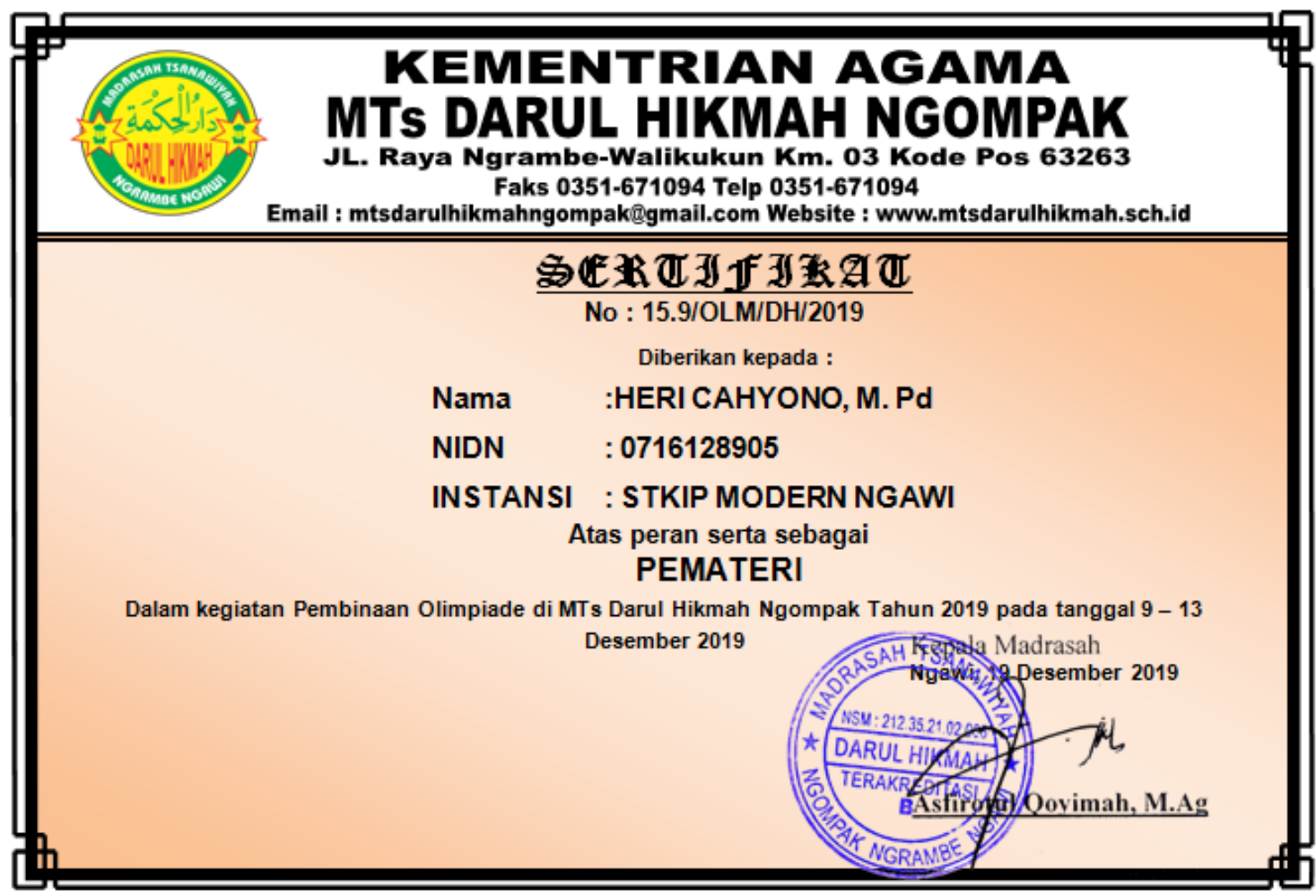

Gambar 1. Sertifikat Pemateri 